\title{
Disputa pelo fundo público no financiamento da educação especial: correlações de forças entre o público e o privado
}

\section{Dispute for the public fund in the financing of special education: correlations of forces between the public and the private Disputa por el fondo público en la financiación de la educación especial: correlaciones de las fuerzas entre el público y el privado}

\author{
MARILEIDE GONÇALVES FRANÇA \\ https://orcid.org/0000-0003-1690-6088 \\ Universidade Federal do Espírito Santo \\ Faculdade de Educação \\ Departamento de Pedagogia \\ Espírito Santo, ES, Brasil \\ ROSÂNGELA GAVIOLI PRIETO \\ https://orcid.org/0000-0003-4013-1163 \\ Universidade de São Paulo \\ Faculdade de Educação
} Núcleo de Políticas de Educação Especial

São Paulo, SP, Brasil

\begin{abstract}
Resumo: O estudo objetiva discutir os argumentos das instituições privadas de educação especial na disputa pelo fundo público no âmbito do Estado, uma análise teoricamente apoiada em Nicos Poulantzas. Para tanto, é realizada análise documental do projeto de lei $\mathrm{n}^{\circ}$ 69. Os resultados apontam que o conteúdo desse projeto desvela argumentos subsidiários à proposta de um modelo de financiamento público, que se concretiza a partir de uma nova forma de relação entre o poder público e tais instituições, em especial as filantrópicas, sob a égide da terceirização dos serviços destinados ao alunado elegível para atendimento pela educação especial.
\end{abstract}

Palavras-chave: Estado. Fundo Público. Financiamento. Educação especial. Público-privado.

\begin{abstract}
The study aims to discuss the arguments of private institutions of special education in the dispute for the public fund within the State, an analysis theoretically supported by Poulantzas (2000). To this end, a documentary analysis of Law 69 is carried out (BRASIL, 2015). The results show that the content of this project unveils subsidiary arguments to the proposal for a public financing model, which takes shape through a new form of relationship between the public power and such institutions, especially philanthropic ones, under the aegis of outsourcing of services. services for students eligible for special education.
\end{abstract}

Keywords:State. Public Fund. Financing. Special education. Public-private. 
Resumen: El estudio tiene como objetivo discutir los argumentos de las instituciones privadas de educación especial en la disputa por el fondo público dentro del Estado, análisis teóricamente apoyado por Poulantzas (2000). Para ello, se realiza un análisis documental del Proyecto de Ley 69 (BRASIL, 2015). Los resultados muestran que el contenido de este proyecto desvela argumentos subsidiarios a la propuesta de un modelo de financiamiento público, que se materializa a partir de una nueva forma de relación entre el poder público y dichas instituciones, especialmente las filantrópicas, bajo la égida de la subcontratación de servicios para estudiantes elegibles para educación especial.

Palabras clave: Estado. Fondo Público Financiación. Educación especial. Público privado.

\section{INTRODUÇÃO}

A garantia do direito à educação às/aos cidadãs/ãos brasileiras/os, prevista no art. 205 da Constituição Federal (BRASIL, 1988), a ampliação de sua oferta e a garantia de ensino de qualidade pressupõem investimento por parte do Estado, pela via do fundo público a ser aplicado em educação escolar, no intuito de minimizar as desigualdades de acesso, permanência e aprendizagem dos diferentes sujeitos nos sistemas educacionais brasileiros.

Tal fundo, segundo Oliveira (1998), constituiu-se no padrão de financiamento público da economia capitalista, na medida em que essa economia perdeu sua capacidade autorregulatória e a esfera do mercado se mostrou insuficiente para tramitar e processar as novas relações sociais. Nessa perspectiva, o Estado configurou-se como instância necessária de publicização, tendo em vista que ele foi forjado para “[...] assegurar os interesses privados, mas só o pode fazer, somente se torna eficaz, se eles se transformam em interesses gerais públicos." (OLIVEIRA, 1998, p. 51).

Assim, ao discutirmos o financiamento da modalidade educação especial, com apoio em constructos teóricos de Poulantzas (2000), partimos do pressuposto de que o Estado brasileiro sofre influência das correlações de forças políticas, econômicas e sociais em torno do fundo público, representadas por diferentes grupos com interesses diversos. Por sua vez, tais forças interferem na constituição das políticas públicas, engendrando implicações na consolidação de direitos de cidadania, entre os quais o direito à educação escolar.

No campo educacional, o desenvolvimento de políticas públicas envolve negociações em torno de diferentes projetos, na tentativa de garantir condições para cumprir os objetivos prescritos pela legislação nacional, inclusive a oferta de educação de qualidade para todas/os. No caso da educação especial, a correlação de forças se estabelece entre distintos grupos sociais no âmbito do Estado, os quais disputam a aplicação de recursos públicos na manutenção e no desenvolvimento de políticas estatais ou na destinação de parcela desses fundos para entidades 
privadas sem fins lucrativos, as instituições especializadas, particularmente as filantrópicas. Diante desse cenário, questiona-se: como se configuram as ações das instituições privadas de educação especial, de caráter filantrópico, no processo de disputa pelos recursos públicos no âmbito do Estado? Nesse sentido, o objetivo proposto neste texto é analisar e discutir argumentos das instituições privadas de educação especial na disputa pelo fundo público, no âmbito do Estado, para o custeio da oferta dos serviços dessa modalidade de ensino, de caráter substitutivo, a partir do projeto de lei no 69 (PL/69), de 4 de março de 2015 (BRASIL, 2015).

Partimos da asserção de que o financiamento da educação especial se constitui como eixo significativo para o processo de formulação, implantação, efetivação e avaliação das políticas públicas educacionais voltadas às/aos alunas/ os com deficiência, transtornos globais de desenvolvimento (TGD) e altas habilidades/superdotação, na medida em que a sua configuração no âmbito do planejamento orçamentário do Estado e a sua destinação entre instituições públicas e privadas são determinantes na oferta e na qualidade de serviços direcionados a esse alunado nos sistemas educacionais (FRANÇA; PRIETO, 2017).

Para o desenvolvimento deste estudo, realizamos análise documental (LÜDKE; ANDRÉ, 1986) do texto do referido PL, por compreendermos que desse documento é possível extrair manifestos e expressões que refletem interesses e proposições defendidas para a política de Estado, relativamente à modalidade educação especial. Do referido projeto, após sucessivas leituras, foram extraídos excertos significativos e representativos de ideias nucleares para responder a pergunta norteadora deste trabalho.

A partir dessas considerações iniciais, é apresentado, na próxima seção, o embasamento sobre financiamento da educação com foco em sua historicidade relativamente à modalidade educação especial, em articulação com constructos de Poulantzas (2000). Na sequência, são situados, descritos e problematizados os aportes normativos necessários à compreensão do contexto de produção do PL/69, as justificativas adotadas para sua defesa e, por fim, as considerações finais.

\section{FINANCIAMENTO DA EDUCAÇÃO ESPECIAL NO CONTEXTO DO ESTADO BRASILEIRO}

Discutir o financiamento da educação como política pública, isto é, como instrumento do Estado capaz de assegurar o direito à educação a uma população historicamente excluída dos processos de escolarização, implica tanto (re)pensar o papel e a relação desse recurso com a sociedade perante as desigualdades sociais quanto reconhecer a natureza contraditória das políticas que afirmam os direitos 
sociais e, ao mesmo tempo, limitam a sua efetivação, de acordo com as correlações de forças decorrentes de disputas entre diferentes classes sociais em torno de projetos distintos.

Assim, não podemos desconsiderar que, no contexto do capitalismo, o Estado pode se distanciar mais ou menos da execução das políticas sociais com vistas a atender aos interesses do capital. Contraditoriamente, é no interior desse mesmo Estado que as correlações de forças se constituem, com possibilidade de promover movimentos de lutas que explicitem reivindicações e necessidades da população ou de seus segmentos, e de lograr resultados positivos. Nessa perspectiva, as lutas populares permeiam a estrutura do Estado com suas relações de produção, sua organização hierárquico-burocrática e sua divisão social de trabalho. As políticas públicas geradas em tal processo são resultantes dessas contradições que permeiam a estrutura do Estado (POULANTZAS, 2000), tornando-o uma expressão condensada da luta de classes sociais em constante desenvolvimento.

No que se refere às políticas de educação especial, historicamente as instituições privadas de educação especial assumiram um lugar privilegiado junto ao Estado brasileiro, seja na ocupação de lugares estratégicos, por exemplo, nas casas legislativas municipais e estaduais, na Câmara de Deputados, no Senado e na composição da coordenação da Secretaria de Educação Especial do Ministério da Educação, seja na influência indireta nas políticas de educação especial (MAZZOTTA, 2011), diante do descaso do Estado brasileiro com políticas e ações garantidoras de condições para o trabalho com essa população nos sistemas educacionais públicos.

Dessa forma, poderíamos supor que, de acordo com Poulantzas (2000), essas instituições tivessem conseguido, em alguns momentos da história da educação brasileira, a hegemonia na ossatura material do Estado, compondo os centros de decisão sobre as políticas de financiamento da educação especial em favor de seus interesses. Desse modo, elas teriam se constituído como uma fração de classe ${ }^{1}$ privilegiada na correlação nas relações de forças no âmbito do Estado.

Em contrapartida, no decorrer das últimas décadas do século $\mathrm{XX}$, essa configuração tem sofrido alterações, por meio do que Poulantzas (2000) denomina fissuras do Estado, em que se dá a inscrição da luta de classes sociais na sua estrutura. Os movimentos sociais, representados por grupos de pessoas com deficiência, pesquisadores do campo da educação especial, associações da

1 Para Poulantzas (1975), as frações de classes correspondem às camadas sociais que se situam, embora de maneira desigual, no âmbito do Estado. O autor cita como exemplos a aristocracia operária, as cúpulas da burocracia e da administração, a burguesia nacional, industrial, comercial e financeira, entre outros. 
área de educação, entre outros, trazem como bandeira de luta a reivindicação pela alocação de recursos públicos voltados ao atendimento educacional especializado (AEE) unicamente em sistemas públicos de ensino.

Cabe destacar que, a partir dos anos 2000 até o impeachment da presidenta Dilma Rousseff em 2016, essas ações têm se constituído também no âmbito do governo federal, considerando a incorporação de representantes da sociedade civil que atuam na defesa dos princípios da inclusão escolar, num intenso processo de negociação perante interesses diversos que compõem o cenário político educacional. Como resultado dessa trajetória, observamos a instituição de políticas públicas que asseguram direitos ao alunado elegível para atendimento pela educação especial, entre os quais o ingresso e a permanência na escola pela via da classe comum, bem como a expansão da oferta de serviços de educação especial de natureza complementar ou suplementar e, portanto, não substitutivo ao ensino oferecido a todas/os.

Esse processo de correlações de forças no âmbito do Estado demonstra o jogo de interesses entre diferentes classes sociais no processo de elaboração de políticas públicas e particularmente na disputa política pelo fundo público no Estado brasileiro, condição indispensável para que tais políticas se efetivem.

No âmbito da organização política brasileira, há várias formas para que uma expressão de luta seja incorporada na legislação. Uma delas é tornar-se pauta de representante no Congresso Nacional, seja na Câmara dos Deputados ou no Senado, o qual a submete na forma de um PL. Como anteriormente explicitado, nesse caso, se configurou no PL no 69/2015 (BRASIL, 2015), a seguir explorado. $\mathrm{Na}$ próxima seção, apresentamos como tal cenário tem se constituído, nos últimos anos, na área do financiamento da educação especial no Brasil, a partir do movimento das instituições privadas, de caráter filantrópico, com a atuação exclusiva na educação especial.

\section{PROJETO DE LEI No 69/2015: INVESTIMENTO DE SETORES SOCIAIS PARA GARANTIR A CONTINUIDADE DE RECURSOS PÚBLICOS ÀS INSTITUIÇÕES PRIVADAS DE EDUCAÇÃO ESPECIAL}

Historicamente, no Brasil, instituições privadas, sem fins lucrativos, de educação especial se constituíram como um serviço paralelo para atendimento às pessoas com deficiência (KASSAR, 2011), porém mantiveram forte relação de dependência econômica com o Estado e a sociedade civil, principalmente no que se refere à obtenção de recursos públicos. 
A luta histórica das instituições com atuação exclusiva em educação especial constitui em se afirmar como escola no sistema educacional brasileiro. Assim, deveriam ser reconhecidas no âmbito normativo e ter assegurado seu financiamento público (SILVA, 2017). Essa configuração possibilitaria a garantia legal de sua existência no cenário da educação brasileira, como serviço de educação especial, e a sua participação na elaboração das políticas de educação especial e na formação de professores, assim como asseguraria recursos públicos voltados à sua manutenção e ao seu desenvolvimento. Marques (2015, p. 35) afirma que o reconhecimento dessas instituições como escolas garante " $[. .$.$] direito e acesso$ a todos os convênios e investimentos de órgãos públicos, mesmo sendo uma instituição privada [...]." Desse modo, o fundo público torna-se objeto de disputas entre os diferentes grupos sociais que compõem o Estado, na tentativa de garantir a consolidação dos seus interesses e projetos.

No que se refere ao financiamento da educação, a partir da implantação da política de fundos, inicialmente com o Fundo de Manutenção e Desenvolvimento do Ensino Fundamental e de Valorização do Magistério (Fundef) ${ }^{2}$ e, posteriormente, com o Fundo de Manutenção e Desenvolvimento da Educação Básica e de Valorização dos Profissionais da Educação ${ }^{3}$ (Fundeb), as instituições especializadas de educação especial, sem fins lucrativos, disputam sua participação no fundo público, por meio de termos de colaboração, projetos e processos de terceirização, os quais se concretizam por meio do "[...] processo de transferência, para o setor privado, de serviços caracterizados como auxiliares ou de apoio às atividades desenvolvidas pelo Estado.” (ADRIÃO; BORGHI, 2008, p. 100).

O Fundeb passou ao abranger toda a educação básica, por meio de seu mecanismo de distribuição de recursos segundo o número de alunas/os das diversas etapas e modalidades de ensino, informado no Censo Escolar do ano anterior, sendo computadas/os as/os alunas/os matriculadas/os nos respectivos âmbitos de atuação prioritária, conforme previsto no art. 211 da Constituição Federal (BRASIL, 1988). Na versão final do Fundeb, foram acrescentadas as matrículas da educação infantil e da educação especial da rede conveniada sem fins lucrativos, com o mesmo peso das do ensino público.

A distribuição de recursos também considera os fatores de ponderação que são definidos anualmente pela Comissão Intergovernamental de Financiamento para a Educação Básica de Qualidade, conforme previsto no inciso I, art. 13 da lei $\mathrm{n}^{\circ}$ 11. 494 (BRASIL, 2007b). A posição de cada especificidade nessa

2 O Fundef foi regulamentado pela lei n ${ }^{\circ}$ 9.424, de 24 de dezembro de 1996, como fundo de natureza contábil em cada unidade da federação, tendo vigorado até o ano de 2006 (BRASIL, 1996b).

3 O Fundeb foi regulamentado pela lei $n^{\circ} 11.494$, de 20 de junho de 2007 e pelo decreto $n^{\circ} 6.253$, de 13 de novembro de 2007 (BRASIL, 2007a), em substituição ao Fundef, com período de vigência de 2007 a 2020. 
escala toma como referência o fator de ponderação de valor 1,0 definido para a matrícula em unidades educacionais urbanas das/dos séries/anos iniciais do ensino fundamental. O valor mínimo por aluna/o-ano da educação especial passa a receber um peso ponderado $20 \%$ superior ao valor por aluna/o de referência, em uma escala cujo valor mais elevado alcança $30 \%$.

Outra normativa importante em relação ao financiamento da educação especial no Fundeb foi o decreto no 7.611, de 17 de novembro de 2011 (BRASIL, 2011), que alterou o decreto $n^{\circ}$ 6.253, de 13 de novembro de 2007 (BRASIL, 2007a). Tal decreto dispõe sobre o Fundeb e passou a vigorar acrescido do art. 9'-A: "Para efeito da distribuição dos recursos do FUNDEB, será admitida a dupla matrícula dos estudantes da educação regular da rede pública que recebem atendimento educacional especializado [...]". Assim, as/os alunas/os com deficiência, TGD e altas habilidades/superdotação passaram a ser contabilizados duplamente no âmbito do Fundeb, quando matriculados em classes comuns e no AEE, podendo esse atendimento ser realizado na mesma escola que a/o aluna/o frequenta, em outra do seu entorno ou por instituições comunitárias, confessionais ou filantrópicas sem fins lucrativos, que ofereçam esse tipo de serviço. Dessa forma, evidencia-se uma mudança na regulamentação dessas instituições, que passam a ser caracterizadas como "terceiro setor", consolidandoas como instituições prestadoras de serviços. Desse modo:

Com a regulamentação do AEE nas instituições privado-filantrópicas, especialmente nas Apaes ${ }^{4}$, essas instituições começaram a receber o financiamento por atendimento prestado, sem precisar mais disputar os recursos por convênios ou projetos, mas agora por dentro do aparelho do Estado, com atendimento direto [...] A Fenapaes se posicionou nessa estrutura como aparelho privado de hegemonia e luta para manutenção de seu status quo institucional nas relações de poder do Estado Integral. (LEHMKUHL, 2018, p. 111).

Nesse cenário, se insere o PL/69, que dispõe "[...] sobre a contratação de Apaes e Pestalozzis, entidades sem fins lucrativos, como prestadoras de serviços do poder público, com especialização em educação especial e dá outras providências" (BRASIL, 2015).

A submissão do PL/69 ao Congresso Nacional foi realizada no mês de março de 2015, pelo Senador Romário de Souza Faria, do Partido Socialista Brasileiro (PSB), que, na sua trajetória política (como deputado federal no ano de 2010 e, a partir de 2014, como senador), vem se envolvendo com a defesa dos direitos da pessoa com deficiência e doenças raras. Apresentamos, em linhas gerais, os objetivos do PL/69, os atores/participantes nessa discussão, as justificativas 
e o seu processo de tramitação no âmbito do Congresso brasileiro, articulados à discussão sobre as correlações de forças na disputa pelo financiamento da educação especial.

O PL/69 foi estruturado em oito artigos, articulados a uma justificativa que expressa como deve ser realizada a contratação das instituições especializadas privadas, de caráter filantrópico, pelo poder público, para ofertar serviços de atendimento na modalidade educação especial. Nesse sentido, estabelece:

Art. $1^{\circ}$. Esta Lei dispõe sobre a contratação de APAES (Associação de Pais e Amigos dos Excepcionais) e PESTALOZZIS, entidades sem fins lucrativos, como prestadoras de serviços do Poder Público, com especialização em educação especial, para o atendimento de alunos com deficiência intelectual ou múltipla, sem limite de idade. (BRASIL, 2015, p. 1).

Evidencia-se que o PL/ 69 define como instituições a serem contratadas, com atuação exclusiva em educação especial, nomeadamente Apaes e Pestalozzis, para o atendimento às/aos alunas/os com deficiência e, com isso, dá demonstrações de defesa de interesses. Cabe ressaltar que também foram delimitados os sujeitos a serem atendidos por essas instituições — os com deficiência intelectual ou múltipla - que, por sua vez, corresponde ao público atendido historicamente por essas instituições e que supostamente não se beneficiariam da escolarização em classe comum. Ademais, os classificados na primeira categoria sempre representaram o maior número de alunas/os indicadas/os para atendimento pela educação especial. Chama atenção a não restrição da idade e, portanto, deixa aberta a possibilidade de haver atendimento substitutivo desde o nascimento à vida adulta. Note-se que não se trata de defender a prestação de serviço de caráter socioeducacional junto a adultos na tentativa de garantir a aprendizagem ao longo da vida, como preconizado por recente alteração legal 5 . Também é importante observar que se trata de atendimento, o que contempla tanto a prestação de serviço de caráter médico-psicológico, o substitutivo, que neste último caso conflitaria com os princípios da inclusão adotados pelo Brasil, após 2008, como o complementar.

A proposta reafirma a configuração das políticas educacionais no Brasil, materializadas por meio da parceria público-privada e, nesse caso em específico, na relação histórica do Estado com as instituições filantrópicas de educação especial, para cumprir o dever de oferta de serviços especializados à população

$5 \quad$ Pela lei $n^{\circ} 13.632$ (BRASIL, 2018) foi alterado o $\int 3^{\circ}$ do art. 58 da Lei de Diretrizes e Bases da Educação Nacional (BRASIL, 1996a) e introduzida a parte grifada: "A oferta de educação especial, nos termos do caput deste artigo, tem início na educação infantil e estende-se ao longo da vida, observados o inciso III do art. $4^{\circ}$ e o parágrafo único do art. 60 desta Lei." 
com deficiência. Cumpre destacar que, dentro da lógica do capitalismo e das mudanças das relações sociais que o fundamentam, nos séculos XX e XXI houve a redefinição do papel do Estado na execução e no financiamento das políticas sociais (BEHRING, 2008), entre as quais as educacionais, que se materializam na divisão de responsabilidades entre o Estado e a sociedade civil no provimento de serviços públicos à população. Os direitos fundamentais, desse modo, deixam de ser compreendidos apenas como dever do Estado e passam a ser concebidos como responsabilidade dos indivíduos e da sociedade civil.

No caso da educação especial, essa parceria se estrutura, segundo Bueno e Kassar (2005), na vinculação do Estado com o terceiro setor — a sociedade civil organizada —, constituído por organizações não estatais que ofertam serviço ao alunado elegível para atendimento pela educação especial, por meio do repasse de recursos públicos a essas instituições.

Faz-se necessário destacar que a garantia do direito das pessoas com deficiência, TGD e altas habilidades/superdotação à educação, no Brasil, assumiu configurações específicas no tocante ao seu processo de concretização. A educação especial iniciou-se atrelada às ações isoladas, desenvolvidas no Ministério da Educação (MEC), desenvolvidas pelas instituições privadas de caráter assistencial, não consideradas pertencentes à rede de ensino brasileira, mas financiadas, em grande parte, com verbas públicas da educação. Somente no final dos anos 1950 e início da década de 1960, a modalidade se tornou política pública, isto é, uma forma de materialização da intervenção estatal na oferta do atendimento pela educação especial — mantido e administrado pelo Estado — nas escolas públicas das redes ou dos sistemas educacionais brasileiros (KASSAR, 2011).

A expansão desse atendimento pela educação especial na rede regular de ensino a partir da década de 1990 se deu sob a égide de um processo de reconfiguração das funções do Estado e das políticas sociais, de cunho neoliberal, revelando o caráter contraditório em que se estabelece o financiamento da educação especial no capitalismo, no qual há o distanciamento do Estado das suas responsabilidades sociais e, ao mesmo tempo, a expansão das políticas direcionadas ao alunado elegível ao atendimento pela educação especial, a partir de recursos públicos destinados às instituições públicas de ensino.

Os parcos recursos financeiros destinados a essa modalidade de ensino foram também compartilhados historicamente com as instituições filantrópicas que tinham centralidade na condução da política e na gestão da educação especial e no provimento de serviços de caráter substitutivo, haja vista que a escolarização dessas pessoas foi pouco priorizada ou assumida pelo Estado ao longo da trajetória da educação brasileira (FERREIRA, 2009). 
No entanto, Garcia (2016, p. 12), ao analisar as políticas de educação especial na perspectiva inclusiva no período de 1995 a 2010, adverte que a ampliação do acesso à educação escolar ocorreu numa conjuntura de gestão da pobreza e na privatização da/na educação, “[...] seja pela participação direta e indireta do setor privado na oferta educacional, seja pela participação do setor privado como formulador ideológico e programático de uma pedagogia do capital para educação escolar pública brasileira [...]", marcadas pelas mudanças estruturais nas formas de organização dos serviços da educação especial.

Assim, aponta que inicialmente as Diretrizes Nacionais para a Educação Especial na Educação Básica (BRASIL, 2001) apresentavam um leque diversificado de estratégias de AEE, voltado ao alunado elegível para atendimento pela educação especial, e eram mantidos os serviços à escola e à classe especial, portanto, o substitutivo. Já a resolução no 4 (MINISTÉRIO DA EDUCAÇÃO, 2009) deu prioridade à implantação de um modelo único de AEE, a ser realizado pelas salas de recursos multifuncionais que, embora possa ser organizado no espaço público das redes de ensino, representando o caráter público da educação especial, pode ter sua gestão privatizada por meio da compra de equipamentos didáticos e/ou participação das instituições privadas na oferta de serviços de educação especial. Desse modo, Garcia (2016, p. 13) sinaliza a ampliação da relação público-privada nas políticas de educação especial em duas vias:

[...] a) com a participação do privado-mercantil mediante a venda de equipamentos para as salas de recursos multifuncionais; e b) frente à não universalização do atendimento educacional especializado, nas redes públicas, destaca-se a participação do privado-assistencial nessa oferta mediante conveniamentos das redes de ensino com instituições filantrópicas.

Diante desse cenário, nos parece que esse PL/69 corresponde a uma tentativa de ratificar a vinculação do Estado com a manutenção e o funcionamento das instituições privadas de educação especial pela via do financiamento, ou seja, contratação para prestação de serviços, mas também para que essas instituições sejam revigoradas para realizar o AEE no contraturno junto às/aos alunas/os matriculadas/os nas escolas comuns, bem como o trabalho substituto da educação especial para aqueles que não se adaptam ao contexto escolar, como observamos no art. $2^{\circ}$ : 
Art. $2^{\circ}$ As APAES e PESTALOZZIS prestarão atendimento educacional, no contraturno, para alunos matriculados em escolas regulares públicas estaduais ou municipais e particulares, a fim de se preservar a política de inclusão.

Parágrafo único. No contrato haverá a observância da matrícula para alunos que não se adaptarem ao ensino regular e os pais ou tutores assinarão uma declaração, formalizando que aquele aluno não frequenta o ensino regular no contraturno por este motivo. (BRASIL, 2015, p. 3).

Portanto, a argumentação em torno da "política de inclusão" é estratégia tanto para apoiar a permanência das/os alunas/os na classe comum quanto para fomentar espaços e formas de atendimento separados, em nome da defesa do acolhimento das necessidades específicas desses sujeitos. Assim, faz-se necessário atentar para as concepções subjacentes aos termos "política de inclusão" e/ou "educação inclusiva", pois podem assumir significado social antagônico a uma concepção de educação pública, gratuita e de qualidade a ser garantida aos sujeitos elegíveis para atendimento pela educação especial, representado por mecanismos que contribuem para a exclusão dessas pessoas da/na escola (FREITAS, 2002).

No parágrafo único do art. $2^{\circ}$ do PL/69, prevê-se a possibilidade de algumas/uns alunas/os que não se adaptarem ao ensino regular frequentarem as instituições privadas de educação especial, desde que os pais ou tutores declarem essa opção, assim formalizando-a. Cabe destacar que a oferta desse atendimento, pela parceria público-privada, está prevista nos art. 58 e 60 da Lei de Diretrizes e Bases da Educação Nacional (BRASIL, 1996a) e no decreto n. 7.611 (BRASIL, 2011) que assegura recursos públicos a essas instituições.

No referido projeto, ainda é afirmada a necessidade de padronização dessas contratações, por legislação específica, prevendo, nos termos do PL/69:

Art. $3^{\circ}$. As contratações serão padronizadas, por legislação específica, considerando-se o custo/aluno per capita por aluno matriculado, considerandose a operacionalização pedagógica, custeio com pessoal e despesas básicas, além de manutenção física, inclusive, no ato da celebração do contrato, deverá constar a ciência do apoio das Secretarias Estaduais de Educação aventadas nos artigos $5^{\circ}$ e $6^{\circ}$ desta Lei.

Parágrafo único. Os termos contratuais deverão considerar a necessidade de reformas e adaptação física, no ato da celebração do contrato, para a devida recepção dos alunos e funcionários. (BRASIL, 2015, p. 1).

Essas disposições constituem formalização legal de reinvindicação histórica das instituições privadas de educação especial, as quais alegam que o valor recebido é aquém do necessário para prover atendimento complementar e/ou substitutivo de qualidade. Daí a necessidade de o Estado garantir recursos exclusivos para esse atendimento, assegurando a autonomia financeira dessas instituições que, segundo o art. $4^{\circ}$ (BRASIL, 2015), como prestadoras de 
serviço, terão autonomia, inclusive para a contratação de seus profissionais. Faz-se necessário interrogar se esse dispositivo asseguraria um profissional com formação docente exigida pela legislação nacional ou poderia resultar na contratação de profissionais com mínima ou sem nenhuma formação na área de educação especial. E, nesse caso, os salários poderiam ser menores, resultando em redução de custos? Cumpre destacar que esse tipo de parceria, se articula à concepção neoliberal de gestão pública, fundamentada na racionalidade do custo/benefício (GARCIA, 2016). Ao deslocar a responsabilidade de contratação para instituições privadas, de caráter filantrópico, o Estado se desresponsabiliza pelo trabalho desenvolvido pelos profissionais da educação especial. Assim, a gestão administrativa e pedagógica, bem como o acompanhamento e a avaliação da atuação desses profissionais, ficam sob a responsabilidade dessas instituições, mesmo que os subsídios financeiros sejam estatais em sua totalidade ou não.

Além disso, no PL/69, é ressaltada a importância do apoio das secretarias estaduais de educação nas ações elencadas nos art. $5^{\circ}$ e $6^{\circ}$, ou seja, no desenvolvimento do projeto político-pedagógico e na gestão dos recursos, conforme segue:

Art. $5^{\circ}$ As Secretarias Estaduais de Educação deverão auxiliar as APAES e PESTALOZZIS no desenvolvimento de projeto político-pedagógico a fim de unificar a excelência no atendimento.

Art. $6^{\circ}$ As Secretarias Estaduais de Educação deverão auxiliar as APAES e PESTALOZZIS na gestão contábil das entidades, visando sua sustentabilidade financeira. (BRASIL, 2015, p. 1).

Observa-se, nesses dispositivos, a tentativa de garantir que as instituições privadas, de caráter filantrópico, se constituam como escolas, a partir da elaboração de projetos políticos pedagógicos e da gestão dos seus recursos. No entanto, o caráter escolar vai além desses dois aspectos, abrangendo uma ação intencional, voltada à apropriação dos conhecimentos historicamente produzidos pela humanidade, a partir de uma prática sistematizada e planejada, assim como uma organização curricular que dialogue com a cultura (PARO, 2010) e a oferta das diferentes etapas e modalidades de ensino a todas/os as/os cidadãs/ãos. A fragilização da dimensão pedagógica no processo de atendimento ao alunado elegível para atendimento pela educação especial, nessas instituições, foi um aspecto bastante criticado ao longo da história e trata-se de um dos argumentos para a defesa de que o trabalho com essa população deve se desenvolver no contexto escolar da classe comum. Nesse sentido, observa-se que a relação público-privada se firma pela exigência de proposta pedagógica, infraestrutura física e autonomia da gestão de recursos financeiros. Se, de um lado, lançar mão do auxílio de secretarias estaduais de educação pode significar aproximação de 
diretrizes político-pedagógicas das instituições com os sistemas ou redes de ensino públicos dessa esfera administrativa, de outro, pode resultar na utilização do fundo público na prestação desse serviço ao setor privado. Ademais, o PL/69 não trata da esfera municipal, apesar de muito do atendimento escolar desse alunado ser realizado por municípios brasileiros.

\title{
NOVOS E/OU ANTIGOS DISCURSOS: A JUSTIFICATIVA DO PL/69
}

$\mathrm{Na}$ justificativa do PL, foram apresentados alguns aspectos que têm marcado a relação do Estado com as instituições privadas, sem fins lucrativos, de educação especial, no que se refere ao financiamento público para a oferta de serviços ao alunado elegível para atendimento pela educação especial. Nos termos do documento, assim é explicitada a justificação:

\begin{abstract}
A atual forma de parceria, entre essas entidades sem fins lucrativos com os governos, é através de convênios e repasse do FUNDEB, que são problemáticas e tem gerado situações de abandono em várias APAES no Brasil todo.

Por não ser algo unificado, esses acordos variam de Estado para Estado e Município pra Município, por isso existem APAES funcionando em condições plenas e outras em condições lamentáveis. (BRASIL, 2015, p. 2).
\end{abstract}

Desse modo, o texto ressalta que a atual forma de parceria, realizada por meio de convênios ${ }^{6}$ e repasses do Fundeb às instituições filantrópicas de educação especial, assim como os diversos "acordos" nos estados e municípios para o provimento de recursos financeiros voltados às suas ações, não têm sido suficientes para a manutenção e o desenvolvimento de suas atividades com qualidade.

Nessa perspectiva, a proposta de termos de colaboração do poder público com as Apaes e Pestalozzis visa, de acordo com o PL, "[...] unificar a qualidade do serviço prestado, inclusive prestando o devido auxílio para que elas tenham autonomia e sustentabilidade financeira [...]” (BRASIL, 2015, p. 2). Essas instituições recebem historicamente recursos públicos para sua manutenção e seu funcionamento, tanto da área da educação quanto de outras áreas, como saúde e assistência social.

6 Cabe destacar que a lei $\mathrm{n}^{\circ} 13.204$, de 14 de dezembro de 2015, altera a lei $\mathrm{n}^{\circ}$ 13.019, de 31 de julho de 2014, e “[...] estabelece o regime jurídico das parcerias entre a administração pública e as organizações da sociedade civil, em regime de mútua cooperação, para a consecução de finalidades de interesse público e recíproco, mediante a execução de atividades ou de projetos previamente estabelecidos em planos de trabalho inseridos em termos de colaboração, em termos de fomento ou em acordos de cooperação." (Grifos nossos). 
No entanto, nos últimos anos, principalmente a partir da implementação do Fundeb (BRASIL, 2007b), houve um aumento de recursos voltados à educação especial nos sistemas educacionais públicos, conforme apontado por França (2018), a partir da diferenciação nos valores de ponderação no âmbito do fundo. Tal alteração tem provocado, nessas instituições, a preocupação quanto à manutenção da regularidade de repasses de recursos financeiros e promovido a sua constante movimentação com o propósito de garantir a sua preservação, pois, "[...] se a presença do setor privado é reconhecida pelo poder público como uma colaboração importante para a efetivação de formas diferenciadas de atendimento, para o setor privado, a busca por recursos públicos é fundamental para sua existência [...]." (LAPLANE; CAIADO; KASSAR, 2016, p. 42). Esses argumentos corroboram, no âmbito do PL/69, a necessidade de criar mecanismos que garantam o repasse regulamentado e contínuo de verbas públicas para o seu funcionamento. A questão que se coloca não é apenas manter ou não essas instituições privadas, de educação especial, com recursos públicos da educação geral, que por si é um problema pelos argumentos já apresentados, mas é também manter o atendimento segregado, contrariando assim a perspectiva inclusiva que estava em processo de construção no Brasil, a partir da Política Nacional de Educação Especial na perspectiva da Educação Inclusiva (PNEE-EI) (BRASIL, 2008).

De acordo com o texto do PL/69, “[...] o terceiro setor merece a atenção do poder público, pois está suprindo uma falha no seu próprio sistema, ao gerar serviços de caráter público, a fim de ocupar as lacunas deixadas pelos governos estaduais [...]." (BRASIL, 2015, p. 3). Benatti (2011), ao discutir o financiamento da educação especial, enfatiza a expressividade do terceiro setor que, constituído por organizações da sociedade civil e em parceria com o Estado, assume os serviços delimitados às políticas sociais, entre as quais as de educação especial. $\mathrm{O}$ argumento é ardiloso, pois, ao manter o repasse, continua desonerando o Estado de cumprir seus deveres, nesse caso o de universalizar o acesso de pessoas com deficiência, TGD e altas habilidades/superdotação às escolas comuns das redes e dos sistemas públicos de ensino; ao mesmo tempo não corroborando a consolidação da educação inclusiva, pois mantém serviços especializados exclusivos.

Ao final do texto de justificativa do PL, o relator apresentou a sugestão de elaboração de políticas públicas que assegurem a regulamentação dos serviços ofertados pelas instituições privadas de cunho filantrópico, na tentativa de garantir o atendimento especializado na rede privada, fazendo uso do seguinte argumento: 
Desta forma, deverão existir políticas públicas colaborativas entre os setores do executivo que poderão aproveitar essa força de trabalho especializado, fornecendo o suporte necessário para sua manutenção e excelência, ao invés de se iniciar do zero um serviço que irá demorar anos para ser idealizado, sem saber de fato se irá sair do papel. (BRASIL, 2015, p. 2).

No entanto, essa alegação dá como certo o conhecimento por essa "força de trabalho" sobre o atendimento do alunado na perspectiva inclusiva, quando se sabe que sua atuação foi marcada pelos princípios do atendimento e do apoio pelo modelo denominado integração e por uma orientação médico-psicológica e não social.

Ainda, essa ação seria mais eficaz e rápida considerando o longo tempo despendido para o investimento do Estado em materializar a política de AEE no contexto da escola. Segundo Meletti (2006, p. 47), a "parceria" é um "bom negócio" para as instituições e para o Estado, porque "[...] o custo da sustentação da instituição especial privada assistencial é inferior ao custo de implementar serviços de educação especial para toda a população com deficiência na rede regular de ensino." Nessa perspectiva, observa-se a tentativa de (re)afirmar o espaço privado especializado, como lugar de excelência para o trabalho junto ao alunado elegível para atendimento pela educação especial, além de tentar assegurar uma dimensão pedagógica a essas instituições.

Outra justificativa para o PL/69 se baseia na experiência realizada no Espírito Santo, a partir da contratação de serviços das Apaes e Pestalozzis, pelo governo estadual, por meio da secretaria de educação, para a oferta do AEE. Oliveira (2016), ao analisar o financiamento da educação especial no estado do Espírito Santo, enfatiza que a mudança da relação do Estado com essas instituições, realizada em 2014, de convênio para contrato de serviços com a finalidade de ofertar AEE, culminou no aumento de recursos públicos a elas destinados. Desse modo, o governo do estado do Espírito Santo continua a investir nas instituições especializadas privadas para ampliação do atendimento a alunas/os elegíveis para atendimento pela educação especial, sob a égide da terceirização.

A apresentação do PL/69 ao Congresso Nacional foi realizada no mês de março de 2015, como anteriormente mencionado. Em dezembro de 2016, o projeto foi encaminhado à Comissão de Constituição, Justiça e Cidadania e ainda continua, em 2020, em fase de tramitação no Senado, conforme informação constante no Portal de Atividade Legislativa do Senado. Cumpre destacar que o 
decreto n. ${ }^{\circ} 10.502$, de 30 de setembro de $2020^{7}$, que institui a Política Nacional de Educação Especial: Equitativa, Inclusiva e com Aprendizado ao Longo da Vida, integra os argumentos apresentados pelo PL/69 no seu texto.

\section{CONSIDERAÇÕES FINAIS}

As análises e discussões apontam que o conteúdo desse projeto constitui uma tentativa de formalizar legalmente, a partir do PL/69, a relação entre o poder público e as instituições privadas de educação especial, sob a égide da terceirização dos serviços públicos destinados aos alunos com deficiência, TGD e altas habilidades/superdotação, por meio da lógica do mercado, na forma de gestão da educação pública que assume as diretrizes da gestão empresarial.

Essa proposta pode vir a representar, caso seja aprovada, alterações no financiamento da educação especial, especialmente na forma de direcionar recursos públicos às instituições privadas, pois, além das verbas asseguradas no Fundeb, que podem ser destinadas a essas instituições pela matrícula do AEE, há a previsão de recursos adicionais pela via da contratação de instituições privadas sem fins lucrativos, como prestadoras de serviços ao poder público, normatizada com detalhamento na lei maior da educação. Tais alterações certamente resultarão na precarização do financiamento voltado às escolas públicas e que deve ser aplicado na melhoria da educação com vistas à consolidação da política de educação inclusiva.

Assim, vislumbramos duas consequências articuladas a esse PL/69: a primeira refere-se à parceria do Estado com as instituições privadas, de cunho filantrópico, que mantêm, em tese, os princípios da inclusão escolar, pois assumem a reponsabilidade pela oferta de AEE complementar ou suplementar à educação comum ou geral na medida da ausência desse serviço fornecido diretamente pelo Estado. Em outras palavras, se aprovado, o projeto autoriza que tais instituições ofereçam esse atendimento na correspondência da necessidade de todas/os aquelas/es que dele puderem se beneficiar, para cobrir a ausência ou a precariedade da política estatal.

A segunda diz respeito à expansão desse atendimento, que pode ser realizada em duas dimensões: pela ampliação de sua oferta no contexto da escola, sem a retirada da/o aluna/o da classe comum no momento de sua/s aula/s, em

$7 \quad$ Esse decreto foi suspenso no mês de dezembro de 2020, pelo ministro Dias Toffoli, do Supremo Tribunal Federal, que o considerou como ação direta de inconstitucionalidade. Disponível em: https://www. conjur.com.br/dl/voto-toffoli-suspensao-decreto-governo.pdf. Acesso em: 28 dez. 2020. 
articulação com o trabalho pedagógico da/o professora/or regente, ou pela via da expansão de matrículas nas escolas especializadas, com fins supostamente escolares e, portanto, substituindo o atendimento por meio da classe comum.

As questões delineadas no texto constituem-se tentativas de promover reflexões que permitam avançar na compreensão sobre o projeto social atual, o qual pressupõe a retomada de propostas conservadoras para essa modalidade de ensino e a defesa da gestão pública sob a orientação das relações capitalistas de mercado para a área de educação especial.

Nessa perspectiva, um ensino de qualidade em todos os níveis e modalidades de ensino está articulado ao aumento do fundo público para a educação pública, à gestão democrática da educação, ao controle social e à definição do regime de colaboração entre os entes federados, conforme foi estabelecido no Plano Nacional de Educação 2014-2024, na Meta 20 (BRASIL, 2014). Pressupõe ainda um redimensionamento das relações público-privadas, que têm marcado a história da educação especial no contexto da educação brasileira, no intuito de universalizar o ingresso desde a creche, no âmbito da educação infantil, à superior, e conferir qualidade ao atendimento daquelas/es classificadas/os nas categorias com deficiência, TGD e altas habilidades/superdotação.

\section{REFERÊNCIAS}

ADRIÃO, Theresa; BORGHI, Raquel. Parcerias entre prefeituras e a esfera privada: estratégias privatizantes para a oferta da educação pública em São Paulo? In: ADRIÃO, Theresa; PERONI, Vera Maria Vidal (Org.). Público e privado na educação: novos elementos para o debate. São Paulo: Xamã, 2008. p. 99-100.

BEHRING, Elaine. Brasil e contra-reforma: desestruturação do Estado e perda de direitos. São Paulo: Cortez, 2008.

BENATTI, Marielle Moreira Santos. O financiamento público das instituições nãoestatais de educação especial em Campo Grande - (2001-2005). In: CONGRESSO BRASILEIRO MULTIDISCIPLINAR DE EDUCAÇÃO ESPECIAL, 6.; ENCONTRO DA ASSOCIAÇÃO BRASILEIRA DE PESQUISADORES EM EDUCAÇÃO ESPECIAL, 7., 2011, Londrina. Anais [...]. Londrina: UEL, 2011.p. 3478-3488.

BRASIL. Constituição (1988). Constituição [da] República Federativa do Brasil. Disponível em: https://bit.ly/2H0SpiU. Acesso em: 18 nov. 2017. 
BRASIL. Decreto $\mathbf{n}^{\mathbf{0}} \mathbf{6 . 2 5 3}$, de 13 de novembro de 2007. Dispõe sobre o Fundo de Manutenção e Desenvolvimento da Educação Básica e de Valorização dos Profissionais da Educação - FUNDEB, regulamenta a Lei no.11.494, de 20 de junho de 2007, e dá outras providências. 2007a. Disponível em: https://bit. ly/2ZTnwVR. Acesso em: 15 dez. 2019.

BRASIL. Decreto $\mathbf{n}^{\circ} \mathbf{7 . 6 1 1}$, de 17 de novembro de 2011. Dispõe sobre a educação especial, o atendimento educacional especializado e dá outras providências. Brasília: Presidência da República, 2011. Disponível em: https://bit.ly/2TTks8B. Acesso em 22 fev. 2018.

BRASIL. Decreto $\mathbf{n}^{\mathbf{0}} \mathbf{1 0 . 5 0 2}$, de 30 de setembro de 2020. Institui a Política Nacional de Educação Especial: Equitativa, Inclusiva e com Aprendizado ao Longo da Vida. Disponível em: http://www.planalto.gov.br/ccivil_03/_ ato2019-2022/2020/decreto/D10502.htm\#: :text=Institui $\% 20 \mathrm{a} \% 20$ Pol\%C3\%ADtica \%20Nacional\%20de,Aprendizado\%20ao\%20Longo\%20 da $\% 20$ Vida. Acesso em: 28 dez. 2020.

BRASIL. Diretrizes nacionais para a educação especial na educação básica. Brasília: Ministério da Educação, 2001.

BRASIL. Lei $\mathbf{n}^{\circ}$ 11.494, de 20 de junho de 2007. Regulamenta o Fundo de Manutenção e Desenvolvimento da Educação Básica e de Valorização dos Profissionais da Educação - FUNDEB. 2007b. Disponível em: https://bit. ly/1rXyQZ7. Acesso em: 15 out. 2017.

BRASIL. Lei $\mathrm{n}^{\circ}$ 9.394, de 20 de dezembro de 1996. Estabelece as diretrizes e bases da educação nacional. 1996a. Disponível em: https://bit.ly/2fWX88v. Acesso em: 04 dez. 2017.

BRASIL. Lei $\mathrm{n}^{\circ}$ 13.005, 25 de junho de 2014. Aprova o Plano Nacional de Educação - PNE e dá outras providências. Diário Oficial [da] República Federativa do Brasil, Brasília, 26 jun. 2014. Seção 1, p.1. 
BRASIL. Lei $\mathbf{n}^{\mathbf{0}} \mathbf{1 3 . 2 0 4}$, de 14 de dezembro de 2015. Altera a Lei no 13.019, de 31 de julho de 2014, "que estabelece o regime jurídico das parcerias voluntárias, envolvendo ou não transferências de recursos financeiros, entre a administração pública e as organizações da sociedade civil, em regime de mútua cooperação, para a consecução de finalidades de interesse público; define diretrizes para a política de fomento e de colaboração com organizações da sociedade civil; institui o termo de colaboração e o termo de fomento; e altera as Leis $\mathrm{n}^{\circ} 8.429$, de 2 de junho de 1992, e 9.790, de 23 de março de 1999"; altera as Leis n ${ }^{\circ} 8.429$, de 2 de junho de 1992, 9.790, de 23 de março de 1999, 9.249, de 26 de dezembro de 1995, 9.532, de 10 de dezembro de 1997, 12.101, de 27 de novembro de 2009, e 8.666, de 21 de junho de 1993; e revoga a Lei no 91, de 28 de agosto de 1935. Disponível em: www.planalto.gov.br/ccivil_03/_Ato2015-2018/2015/Lei/L13204.htm. Acesso em 28 dez. 2020.

BRASIL. Lei $\mathbf{n}^{\mathbf{0}}$ 13.632, de 6 de março de 2018. Altera a Lei no 9.394, de 20 de dezembro de 1996 (Lei de Diretrizes e Bases da Educação Nacional), para dispor sobre educação e aprendizagem ao longo da vida. Disponível em: https://bit. ly/2MWeltD. Acesso em: 15 jun.2019.

BRASIL. Lei no 9.424, de 24 de dezembro de 1996. Dispõe sobre o Fundo de Manutenção e Desenvolvimento do Ensino Fundamental e de Valorização do Magistério. Diário Oficial [da] República Federativa do Brasil, Brasília, 26 dez. 1996b. Seção 1.

BRASIL. Política Nacional de Educação Especial na perspectiva da Educação Inclusiva. Brasília, 2008. (Documento elaborado pelo Grupo de Trabalho nomeado pela Portaria $n^{\circ} 555 / 2007$, prorrogada pela Portaria $n^{\circ}$ 948/2007, entregue ao Ministro da Educação em 07 de janeiro de 2008).

BRASIL. Senado. Projeto de Lei ${ }^{\circ}$ 69, de 4 de março de 2015. Dispõe sobre a contratação de APAES e PESTALOZZIS, entidades sem fins lucrativos, como prestadoras de serviços do Poder Público, com especialização em educação especial e dá outras providências. 2015. Disponível em: https://legis.senado.leg. $\mathrm{br} /$ sdleggetter $/$ documento?dm $=2922611 \& \mathrm{ts}=1567532880357 \&$ disposition=inli ne. Acesso em: 15 jun.2019. 
BUENO, Carmelita Cristina; KASSAR, Mônica de Carvalho Magalhães. Público e Privado: a educação especial na dança de possibilidades. In: ADRIÃO, Theresa; PERONI, Vera. O público e o privado na educação: interfaces entre Estado e sociedade. São Paulo: Xamã, 2005.

FERREIRA, Júlio Romero. Financiamento da educação básica: o público e o privado na educação especial brasileira. In: FÁVERO, Osmar et al. Tornar a educação inclusiva. Brasília: UNESCO, 2009. p. 55-64.

FRANÇA, Marileide Gonçalves. Financiamento da educação especial no âmbito do Fundeb: limites e desafios. In: PRIETO, Rosângela Gavioli; KUMADA, Kate Mamby Oliveira; BRITO, Fábio Bezerra de; ANDRIOLI, Mary Grace Pereira (Org.). Políticas de educação especial. Curitiba: CRV, 2018.

FRANÇA, Marileide Gonçalves; PRIETO, Rosângela Gavioli. Gestão dos recursos voltados à educação especial em município brasileiro (2008-2014). Educação em Revista, Belo Horizonte, n. 33, p. 1-28, set. 2017.

FREITAS, Luiz Carlos de. A internalização da exclusão. Educação \& Sociedade, Campinas, v. 23, n. 80, p. 301-327, set. 2002.

GARCIA, Rosalba Maria Cardoso. Educação especial na perspectiva inclusiva: determinantes econômicos e políticos. Comunicações Piracicaba, v. 23, n. 3, p. 7-26, 2016.

KASSAR, Monica de Carvalho Magalhães. Percursos da constituição de uma política brasileira de educação especial inclusiva. Revista Brasileira de Educação Especial, Marília, v. 17, p. 41-58, maio/ago. 2011.

LAPLANE, Adriana Lia Friszman de.; CAIADO, Katia Regina Moreno; KASSAR, Mônica de Carvalho Magalhães. As relações público-privado na educação especial: tendências atuais no Brasil. Revista Teias, Rio de Janeiro, v. 17, n. 46, p. 40-55, jul./set. 2016.

LEHMKUHL, Márcia de Souza. A reconfiguração da Federação Nacional das Apaes (Fenapaes) no estabelecimento da relação entre público e privado nas políticas de educação especial (1974/2016). 2018. Tese (Doutorado em Educação) - Programa de Estudos e Pós-Graduados em Educação, Pontifícia Universidade Católica de São Paulo, São Paulo, 2018. 
LÜDKE, Menga; ANDRÉ, Marli Eliza Dalmazo Afonso de. Pesquisa em educação: abordagens qualitativas. São Paulo: EPU, 1986.

MARQUES, Emanuely Fernandes. Política de Educação Especial e a reestruturação de instituições especiais no Paraná. 2015. 100f. Dissertação (Mestrado em Educação) - Centro de Educação, Comunicação e Artes, Universidade Estadual de Londrina, Londrina, 2015.

MAZZOTTA, Marcos José da Silveira. Educação especial no Brasil: história e políticas públicas. 6.ed. São Paulo: Cortez, 2011.

MELETTI, Sílvia Márcia Ferreira. Educação escolar da pessoa com deficiência mental em instituições de educação especial: da política à instituição concreta. 2006. 125 f. Tese (Doutorado em Psicologia) - Instituto de Psicologia, Universidade de São Paulo, São Paulo, 2006.

MINISTÉRIO DA EDUCAÇÃO (Brasil). Resolução CNE/CEB no 4, de 2 de outubro de 2009. Institui Diretrizes Operacionais para o Atendimento Educacional Especializado na Educação Básica, modalidade Educação Especial. Diário Oficial [da] República Federativa do Brasil, 5 out. 2009. Seção 1, p. 17.

OLIVEIRA, Francisco de. Os direitos do antivalor: a economia política da hegemonia imperfeita. Petrópolis, Rio de Janeiro: Vozes, 1998.

OLIVEIRA, Gildásio Macedo de. Financiamento das instituições especializadas na política de educação especial no Estado do Espírito Santo. 2016. Dissertação (Mestrado em Educação) - Programa de Pós-Graduação em Educação, Universidade Federal do Espírito Santo, Vitória, 2016.

PARO, Vitor. Educação como exercício do poder: crítica ao senso comum em educação. São Paulo: Cortez, 2010.

POULANTZAS, Nicos. As classes sociais no capitalismo de hoje. Rio de Janeiro: Zahar, 1975.

POULANTZAS, Nicos. O Estado, o poder, o socialismo. São Paulo: Paz e Terra, 2000. 
SILVA, João Henrique da. Federação nacional das Apaes no Brasil, hegemonia e propostas educacionais (1990-2015). 2017. Tese (Doutorado em Educação) - Programa de Pós-Graduação em Educação Especial, Universidade Federal de São Carlos, São Carlos, 2017.

\section{Marileide Gonçalves França}

Graduação em pedagogia pela Universidade Federal do Espírito Santo (2005), Mestrado em Educação pela Universidade Federal do Espírito Santo (2008), Doutorado em Educação na Universidade de São Paulo (2014) e atualmente é professora da Universidade Federal do Espírito Santo. Tem experiência na área de Educação, atuando principalmente nos seguintes temas: política educacional; financiamento da educação, formação de professores; planejamento educacional, avaliação educacional, currículo escolar, educação especial e educação das relações étnico-raciais. Vice-coordenadora da Rede Fineesp. E-mail: leidemary8@gmail. com

\section{Rosângela Gavioli Prieto}

Graduada em Pedagogia, com habilitações em Educação do Deficiente pela Pontifícia Universidade Católica de Campinas (1981) e em Administração Escolar pela Universidade de Guarulhos (1987); graduada em Psicologia pela Universidade de Guarulhos (1994); mestre em Educação Especial (Educação do indivíduo especial) pela Universidade Federal de São Carlos (1990); doutora em Educação pela Universidade de São Paulo (2000). Atualmente, é professora da Faculdade de Educação da Universidade de São Paulo, onde foi chefe do Departamento de Administração Escolar e Economia da Educação (2009-2012); é coordenadora do Grupo de pesquisa CNPq Políticas de educação especial desde 2002. Coordenadora da Rede Fineesp. E-mail: rosangel@usp.br 